\title{
Epidemiological perspectives on Hendra virus infection in horses and flying foxes
}

\author{
HE FIELD, ${ }^{a}$ AC BREED, ${ }^{b} \mathrm{~J}$ SHIELD,,${ }^{\mathrm{c}}$ RM HEDLEFS, ${ }^{\mathrm{d}} \mathrm{K}$ PITTARD,,${ }^{\mathrm{e}}$ B POTT ${ }^{\mathrm{f}}$ and PM SUMMERS ${ }^{\mathrm{g}}$
}

Key words: Hendra virus, fruit bats, horses, epidemiology Aust Vet J 2007;85:268-270 doi: 10.1111/j.1751-0813.2007.00170.x

$\mathrm{H}$ endra virus was first described in 1994 in Australia after a sudden outbreak of an acute respiratory syndrome in Thoroughbred horses in a Brisbane racing stable. The syndrome was characterised by severe respiratory signs and high mortality. A previously undescribed virus of the family Paramyxoviridae, initially named equine morbillivirus, was identified as the causal agent. ${ }^{1}$ The virus was later renamed Hendra virus after the Brisbane suburb where the outbreak occurred. Thirteen of 20 infected horses died, and a stablehand and the trainer were infected, the latter fatally. Fruit bats of the genus Pteropus (family Pteropodidae), colloquially known as flying foxes, were subsequently shown to be the likely reservoir host of Hendra virus and the putative source of infection for horses. ${ }^{2,3}$ The second identified outbreak in horses (involving the fatal infection of two horses on a Thoroughbred stud near Mackay in central Queensland) actually preceded the Brisbane outbreak by several weeks but was identified retrospectively after the Hendra virus-attributed death of the stud owner 15 months later. ${ }^{4,5}$ The third known incident involved a single fatal case in a 9-year-old Thoroughbred mare in the Cairns region of northern Queensland in January 1999. ${ }^{6}$ No human cases were involved. Two new cases of Hendra virus infection (or probable infection) in horses in northern Queensland, described below, prompt this review of epidemiological aspects of Hendra virus infection in horses and flying foxes.

On 25 October 2004, a 10-year-old Thoroughbred gelding (Case A), one of eight horses on a 5.6 ha semi-rural property $26 \mathrm{~km}$ south of Cairns, died after an acute illness. During an observed $24 \mathrm{~h}$ clinical course, the horse was reported to be 'off colour', exhibiting restlessness, inappetence, profuse sweating and increased respiratory effort. On veterinary examination,

\footnotetext{
aDepartment of Primary Industries and Fisheries, Yeerongpilly QLD 4105; hume.field@dpi.qld.gov.au

${ }^{b}$ School of Veterinary Science, The University of Queensland, St Lucia QLD 4072

'Department of Primary Industries and Fisheries, Cairns QLD 4870

dDepartment of Primary Industries and Fisheries, Townsville QLD 4810

${ }^{\text {e}}$ Cairns Veterinary Clinic, Manoora QLD 4870

'Townsville Veterinary Clinic, Aitkenvale QLD 4814

gSchool of Veterinary and Biomedical Sciences, James Cook University,

Townsville QLD 4811.
}

the horse was in lateral recumbency with a rectal temperature of $>41^{\circ} \mathrm{C}$, a heart rate of $>120$ beats per minute, distended jugular veins, a capillary refill time of $3 \mathrm{~s}$, injected mucous membranes, severe dyspnoea with a respiratory rate of $>100$ breaths per minute, and a large amount of red froth flowing from the nostrils. He was very weak, unable to stand or hold his head off the ground, but was not rolling or thrashing. The horse died and a necropsy was done. Hendra virus was not considered as a differential diagnosis at the time, and no samples were taken to enable a definitive retrospective diagnosis of Hendra virus infection. The veterinarian who undertook a necropsy reported the onset of influenza-like symptoms on 2 November 2004. Two other people assisting with the necropsy reported similar symptoms. All three were negative for antibodies to Hendra virus by immunofluorescent antibody test (IFT) and enzyme-linked immunosorbent assay (ELISA) at that time. A second sample taken from the veterinarian on 16 November 2004 was positive for antiHendra virus antibodies by IFT and ELISA, and neutralising antibodies to Hendra virus were detected by serum neutralisation test. The symptoms in the two necropsy assistants were attributed to illnesses unrelated to Hendra virus. Case A was regarded as a probable case of Hendra virus infection, and the source of infection to the veterinarian, based on a clinical history consistent with Hendra virus infection, the absence of such clinical history in all 12 horses that the veterinarian had attended in the preceding 8 weeks, and the rising antibody titre exhibited by the veterinarian. Aspects of this case are also reported by Hanna et al. ${ }^{12}$

On 1 December 2004, a solitary 14-year-old Thoroughbred gelding (Case B) on a 0.75 ha semi-rural property $20 \mathrm{~km}$ south of Townsville (and $400 \mathrm{~km}$ south of Case A) was humanely killed after veterinary examination revealed a $40^{\circ} \mathrm{C}$ rectal temperature, moist rales, increased heart rate and toxic mucous membranes. The owners reported that the horse had shown a nasal discharge and a variable appetite during the previous week but had deteriorated in the final $48 \mathrm{~h}$, walking abnormally and repeatedly attempting to lie down (signs suggestive of colic). On necropsy, blood stained froth was present in the trachea and bronchi, the lungs were uniformly congested and oedematous and petechial haemorrhages were present in the apical lobes of the lungs, dorsal thorax and epiglottis. There was no increase in pleural fluid. Microscopic examination of lung tissue revealed extensive alveolar haemorrhage and oedema, necrosis of alveolar macrophages, intra-vascular coagulation, scattered endothelial syncytium and a mononuclear vasculitis. Fibrinoid necrosis of small arteries and associated mild interstitial mononuclear infiltration as well as 
focal necrosis was present in the myocardium. No changes were seen in the liver, spleen, right kidney or gastro-intestinal tract. The cortex of the anterior left kidney was atrophied and the dilated pelvis contained several uroliths, the largest $4 \times 6 \mathrm{~cm}$. A diagnosis of Hendra virus infection was confirmed on the basis of viral antigen detection by immunohistochemical staining and viral RNA detection by PCR. Eighteen people with possible at-risk exposure (including the two veterinarians who performed the clinical examination and necropsy respectively) were negative for neutralising antibodies to Hendra virus on serial blood tests.

The two cases above have a number of features in common with previous index cases, namely breed (Thoroughbred), age ( $>8$ years old), housing (paddocked), season (spring to summer), and presence of flying fox food or roost trees in the horse paddock. ${ }^{6}$ Case A was a 10-year-old Thoroughbred; Case B was a 14-year-old Thoroughbred. Case A grazed pasture under exotic fruit trees and native eucalypts, both seasonally favoured by flying foxes; Case B was primarily handfed (his food bin attached to the trunk of a eucalyptus tree) and grazed a small area adjoining native riparian vegetation, again including seasonally favoured food trees. Natural and experimental infections in horses indicate an incubation period in horses of 8 to $16 \mathrm{~d}^{7}$ and 4 to $10 \mathrm{~d}^{1}$ respectively, so it is likely that Case A was exposed in mid October, and Case B in mid to late November, overlapping the peak September to November birthing season of Pteropus alecto (black flying fox) and $P$ conspicillatus (spectacled flying fox). ${ }^{8}$ Female gender and pregnancy, features common to previous cases, were not features of either case reported here.

While overinterpretation of features of the spillover events to date is unwise given the limited sample size, some consideration of possible patterns is appropriate. These two cases are temporally and spatially clustered, as were the earlier Mackay (August 1994) and Brisbane (September 1994) cases, although the spatial clustering is weaker in the latter. Thus spillover to horses, rather than being sporadic, may reflect an episodic pattern of infection in flying foxes. An outbreak of infection in a colony of flying foxes could result in a peak of virus excretion with a resultant increased probability of exposure and possible infection of horses in the vicinity for a limited time. Such a pattern of pulsating endemicity of infection ${ }^{13}$ in flying foxes would require the attainment of a threshold proportion of susceptible flying foxes within a colony sufficient to support an outbreak, and the subsequent introduction of infection by a nomadic individual or group from a currently infected colony. This process of metapopulation dynamics is well recognised for other paramyxoviruses such as measles ${ }^{10}$ and phocine distemper. ${ }^{11}$ In Australia, flying foxes have the necessary spatially structured population to support metapopulation dynamics, and are seasonally nomadic, and it is plausible that the means by which Hendra virus maintains itself within its reservoir would incorporate these host features.

Spatial clustering of equine cases is also evident on a regional scale, in that all known spillovers to date have been in northeastern Australia (Figure 1). Yet the distribution of neither horses nor flying foxes is restricted to this region. However, north-

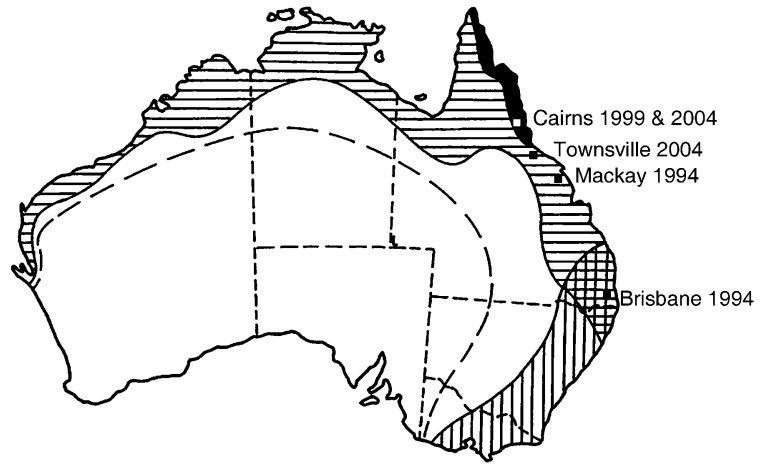

Key: $\quad$ Horizontal hatching $=P$ alecto Vertical hatching $=P$ poliocephalus Solid black $=P$ conspicllatus

Solid black $=P$ conspicllatus

Figure 1. Distribution of flying foxes on mainland Australia and location of Hendra virus spillover events to horses.

Adapted from Hall and Richards, $2000^{8}$

eastern Australia does have the greatest diversity of flying fox species (four species), with $P$ conspicillatus endemic to northern Queensland, and the eastern distribution of $P$ alecto confined to Queensland and northern New South Wales. ${ }^{8}$ Thus, if species and/or species biodiversity are important determinants of the pattern of Hendra virus infection in flying foxes or the risk of spillover, then the limited geographic occurrence in horses to date is plausibly explained. Further investigation of the dynamics of Hendra virus infection in flying foxes and the mode of transmission to horses is warranted.

The recent cases in northern Queensland provide an opportunity to investigate the dynamics of Hendra virus infection in flying foxes. Flying fox colonies were identified in the vicinity of both index case paddocks, and their putative infected status at the time the horses were infected, provides a baseline for proposed longitudinal serologic survey. If a pattern of pulsating endemicity of infection does occur in flying foxes as previously discussed, a peak seroprevalence could be expected immediately post epidemic, with seroprevalence falling over subsequent years as the proportion of susceptible flying foxes increases again. The survey data will be used to test this hypothesis and to support predictive modelling of Hendra virus infection dynamics in flying foxes, and thereby contribute to spillover risk management by identifying any pattern of infection in the reservoir host and thus any periodicity of increased risk of spillover.

\section{Addendum}

Two further cases of Hendra virus infection occurred in northeastern Australia in 2006 in two separate incidents. The first was at Peachester in south-east Queensland (June), and the second at Murwillumbah in northern New South Wales (October). The features of breed (Thoroughbred), age ( $>8$ years old), housing (paddocked), and the presence of flying fox food trees were consistent with previous index cases, and spatial and temporal clustering was again evident. 


\section{Acknowledgments}

The authors acknowledge the owners of both horses for their cooperation during the investigations, the Diagnostic, Response and Surveillance Group at the CSIRO Australian Animal Health Laboratory who conducted the PCR, immunohistochemistry and serology on forwarded samples from Case B, and Carmel Taylor, Ina Smith and Scott Craig at Queensland Health Scientific Services Laboratories who conducted the human serology associated with both cases.

\section{References}

1. Murray K, Selleck $P$, Hooper $P$ et al. A morbillivirus that caused fatal disease in horses and humans. Science 1995;268:94-97.

2. Young PL, Halpin K, Selleck PW et al. Serologic evidence for the presence in Pteropus bats of a paramyxovirus related to equine morbillivirus. Emerg Infect Dis. 1996;2:239-240.

3. Halpin K, Young P, Field H, Mackenzie J. Isolation of Hendra virus from pteropid bats: a natural reservoir of Hendra virus. J Gen Virol 2000;81:1927-1932. 4. Rogers RJ, Douglas IC, Baldock FC et al. Investigation of a second focus of equine morbillivirus infection in coastal Queensland. Aust Vet J 1996;74:243-244.
5. Allworth A, O'Sullivan J, Selvey L, Sheridan J. Equine morbillivirus in Queensland. Communicable Disease Intelligence 1995;19:575.

6. Field H, Barratt P, Hughes R, Shield J, Sullivan N. A fatal case of Hendra virus infection in a horse in north Queensland: clinical and epidemiological features. Aust Vet J 2000;78:279-280.

7. Baldock FC, Douglas IC, Halpin K et al. Epidemiological investigations into the 1994 equine morbillivirus outbreaks in Queensland, Australia. Sing Vet J 1996;20:57-61. 8. Hall L, Richards G. Flying foxes: Fruit and Blossom Bats of Australia. In: Dawson TJ, editor. Australian Natural History Series. University of New South Wales Press Ltd, Sydney, 2000.

9. Field $\mathrm{H}$. The ecology of Hendra virus and Australian bat lyssavirus. PhD thesis, The University of Queensland, Brisbane. http://espace.library.uq.edu.au/ view.php?pid=UQ:13859. 2005.

10. Bolker B, Grenfell B. Space, persistence and dynamics of measles epidemics. Phil Trans R Soc Lond 1995;348:309-320.

11. Swinton J, Harwood J, Grenfell B, Gilligan C. Persistence thresholds for phocine distemper virus infection in harbour seal Phoca vitulina metapopulations. J Anim Ecol 1998;67:54-68.

12. Hanna J, McBride W, Brookes D et al. Hendra virus infection in a veterinarian. MJA 2006:185:562-564.

13. Thrusfield M. Veterinary Epidemiology 2nd edn. Blackwell Science Ltd, Oxford, 1995

(Accepted for publication 28 March 2007) 